Cite this: RSC Adv., 2014, 4, 1347

Received 16th September 2013 Accepted 18th November 2013

DOI: $10.1039 / c 3 r a 45155 k$

www.rsc.org/advances

\section{Site-specific immobilization of microbes using carbon nanotubes and dielectrophoretic force for microfluidic applications $\uparrow$}

\author{
Intae Kim, ${ }^{a}$ Taechang An, ${ }^{\mathrm{b}}$ WooSeok Choi, ${ }^{a}$ Chang Sup Kim, ${ }^{\mathrm{C}}$ Hyung Joon Cha ${ }^{\mathrm{c}}$ \\ and Geunbae Lim*ad
}

We developed a microbial immobilization method for successful applications in microfluidic devices. Single-walled nanotubes and Escherichia coli were aligned between two cantilever electrodes by a positive dielectrophoretic force resulting in a film of single-walled nanotubes with attached Escherichia coli. Because this film has a suspended and porous structure, it has a larger reaction area and higher reactant transfer efficiency than film attached to the substrate surface. The cell density of film was easily controlled by varying the cell concentration of the suspension and varying the electric field. The film showed excellent stability of enzyme activity, as demonstrated by measuring continuous reaction and long-term storage times using recombinant Escherichia coli that expressed organophosphorus hydrolase.

Humans have used microorganisms before they even knew of their existence for such things as brewing and food fermentation. More recently, microbes that have special catalytic activity have been discovered and advancements in metabolic engineering and synthetic biology have enabled the use of microbes for specific metabolic processes and to synthesize specific enzymes. ${ }^{1-5}$ Microbes have been successfully used for various applications, such as wastewater and soil treatment, biofuel cells, biofuel production, hydrogen production, and biosensors., ${ }^{1,5-12}$

The use of microbes in microfluidic applications has the potential to improve established technology and offer new methodologies in many fields. This is because microbes can be

${ }^{a}$ Department of Mechanical Engineering, Pohang University of Science and Technology (POSTECH), San 31, Pohang, Gyungbuk, 790-784, The Republic of Korea. E-mail: limmems@postech.ac.kr

${ }^{b}$ Department of Mechanical Design Engineering, Andong National University, Andong, Gyungbuk, 760-749, The Republic of Korea

'Department of Chemical Engineering, Pohang University of Science and Technology (POSTECH), San 31, Pohang, Gyungbuk, 790-784, The Republic of Korea

${ }^{d}$ Department of Integrative Bioscience and Biotechnology, Pohang University of Science and Technology (POSTECH), San 31, Pohang, Gyungbuk, 790-784, The Republic of Korea

$\dagger$ Electronic supplementary information (ESI) available. See DOI: $10.1039 / \mathrm{c} 3 \mathrm{ra} 45155 \mathrm{k}$ used in place of common enzymes in microfluidic chips. ${ }^{\mathbf{1 3 , 1 4}}$ Microbes are a major host for enzyme production. Useable enzymes are produced as a result of a purification process because the enzymes are expressed in the intracellular space as an inclusion body. Recently, the secretion of enzymes into the periplasmic space or cell surface has been developed. ${ }^{15,16}$ Using this technique, the enzymes in the periplasmic space or cell surface can come into contact with reactants without the need for a purification process. This means microbes can be used as whole-cell catalysts and can replace the use of enzymes. ${ }^{17-21}$ In addition, the metabolic activity of microbes can be used in microfluidic devices. Therefore, macroscale systems that use the metabolic activity of microbes can be miniaturized in microfluidic devices and integrated in microfluidic systems as bioreactors.

To use microbes in microfluidic applications, a microbial immobilization method that allows efficient fixation and exact positioning in a small space is required. Various microbial cell immobilization methods, such as flocculation, chemical attachment, gel entrapment, encapsulation, and biofilms have been developed and are currently used.,12,22-24 However, these methods are unsuited for microfluidic systems due to critical problems, such as mass transport limitations, difficulty in size reduction, non-site-specific immobilization, and slow processing.

The present paper presents a one-step microbial immobilization method for microfluidic applications using single-walled nanotubes (SWNTs), and dielectrophoretic (DEP) force. DEP force is an effective tool when manipulating biological cells and SWNTs. ${ }^{25-28}$ This method is an extension of our film fabrication technique involving dielectrophoretically aligned SWNTs. ${ }^{28}$ In this method, SWNTs were functionalized by oxidation and mixed with an Escherichia coli $(E$. coli) suspension. The mixed suspension of SWNTs and $E$. coli cells was placed between two cantilever electrodes and the $E$. coli and SWNTs were aligned by the DEP force. Finally, an SWNT film with attached E. coli was formed in the desired location. The effectiveness of this immobilization method was demonstrated by density control of the cells and the stability of cell activity. 
In this study, an SWNT suspension was prepared by oxidation of SWNTs in a strong acid solution with sonication..$^{28,29}$ Five milligrams of SWNTs were suspended in $50 \mathrm{~mL}$ of concentrated $\mathrm{H}_{2} \mathrm{SO}_{4}-\mathrm{HNO}_{3}(3: 1, \mathrm{v} / \mathrm{v})$ and sonicated in an ultrasonic bath for $3 \mathrm{~h}$. The SWNT suspension was diluted with $2 \mathrm{~L}$ of deionized (DI) water and collected on a membrane filter (Millipore, MA, USA) by vacuum filtration. Collected SWNTs were resuspended with $50 \mathrm{~mL}$ of DI water so that the $\mathrm{pH}$ of the suspension was neutral. After $24 \mathrm{~h}$, sediments were removed and the SWNT suspension was centrifuged at $12000 \mathrm{rpm}$ for $5 \mathrm{~min}$. The supernatant was decanted, and DI water was added. This process resulted in SWNT bundles with relatively even diameters.

Recombinant $E$. coli cells which express organophosphorous hydrolase $(\mathrm{OPH})$ in the periplasm and chaperone GroEL/ES in the cytoplasm $^{21,30}$ were used as the target microorganism and cultured in Luria-Bertani (LB) medium $(0.5 \%(\mathrm{w} / \mathrm{v})$ yeast extract, $1 \%(\mathrm{w} / \mathrm{v})$ tryptophan, and $1 \%(\mathrm{w} / \mathrm{v}) \mathrm{NaCl})$ containing $50 \mu \mathrm{g} \mathrm{mL}^{-1}$ of ampicillin (Sigma-Aldrich, St. Louis, MO, USA) and $25 \mu \mathrm{g} \mathrm{mL}$ chloramphenicol (Sigma-Aldrich). For efficient expression of recombinant $\mathrm{OPH}$ and GroEL/ES, $1 \mathrm{mM}$ (final concentration) of isopropyl- $\beta$-D-thiogalactopyranoside (IPTG; Sigma-Aldrich), $10 \mathrm{ng}$ $\mathrm{mL}^{-1}$ of tetracycline, and $0.5 \mathrm{mM}$ of $\mathrm{CoCl}_{2}$ were added when the culture reached a cell density $\left(\mathrm{OD}_{600}\right)$ of 1.2 . The recombinant cells were grown for an additional $12 \mathrm{~h}$ at $37{ }^{\circ} \mathrm{C}$. The cells were harvested by centrifugation at $4000 \mathrm{~g}$ for $10 \mathrm{~min}$. The harvested cells were resuspended in Tris-HCl buffer $(\mathrm{pH}$ 8.0) at various densities and diluted tenfold with SWNT suspension.

Scheme 1 is a schematic diagram of the fabrication process for microbe-attached SWNT film. Cantilever electrodes were fabricated using a microelectromechanical system (MEMS). The cantilever structure was formed by depositing a low-stress nitride on the Si substrate using low-pressure chemical vapor deposition (LPCVD, Scheme 1a). Au electrodes were patterned on a silicon nitride surface by a lift-off process (Scheme 1b). To construct the cantilever structure, the silicon nitride was patterned by reactive-ion etching (RIE, Scheme 1c), and the silicon was etched by isotropic wet etching (Scheme 1d).

The SWNT film with attached E. coli was formed between the two cantilever electrodes. To accomplish this, a mixed SWNT-E. coli suspension was placed between the suspended electrodes (Scheme 1e), and AC voltage at an amplitude of 6-10 $\mathrm{V}_{\mathrm{PP}}$ and a frequency of $1 \mathrm{MHz}$ was applied between the two electrodes.
Because both SWNTs and E. coli have higher permittivity than the suspension medium, they were aligned across the electrodes by the positive DEP force (Scheme 1f). At that time, part of the suspension was removed, and the remaining suspension formed a water meniscus between the two electrodes. Thus, the aligned SWNTs and E. coli were compressed and adhered to each other, ${ }^{31}$ and the SWNTs were attached to the electrodes by Van der Waals force. As a result, an SWNT film with attached $E$. coli was formed between the two cantilever electrodes (Scheme $1 \mathrm{~g}$ ). The entire process occurs within one minute (see ESI Video $\mathrm{S} 1 \dagger)$. In comparison to traditional microbial immobilization methods, this method is very fast.

To investigate the stability of the film, continuous reaction time and long term storage stability were evaluated. Paraoxon

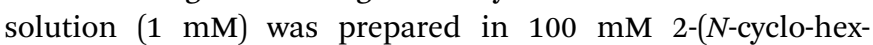
ylamino)ethane-sulfonic acid (CHES) buffer ( $\mathrm{pH}$ 9.0; SigmaAldrich). The solution was used as a reactant and recombinant $E$. coli that expressed $\mathrm{OPH}$ in the periplasmic space was used as a whole-cell catalyst. Paraoxon is hydrolyzed to $p$-nitrophenol (PNP) and diethylphosphoric acid by OPH. Therefore, the catalytic reaction of $\mathrm{OPH}$ can be measured by measuring PNP density. E. coli-attached SWNT film was immersed in a $500 \mu \mathrm{l}$ paraoxon solution $(1 \mathrm{mM})$ for $1 \mathrm{~h}$ at $25{ }^{\circ} \mathrm{C}$. The PNP density of the solution was then determined by using spectrophotometer to measure the absorbance of the solution at $\lambda 400 \mathrm{~nm}$ (Mecasys, Daejeon, Korea). To determine the continuous reaction time, paraoxon solution in which SWNT film was immersed was changed every one hour for $18 \mathrm{~h}$ and the PNP density of the removed solution was measured. To investigate the long-term storage stability of the microbe-attached SWNT film, the film was stored at $4{ }^{\circ} \mathrm{C}$ and every 3 days, the film was immersed in $500 \mu \mathrm{l}$ paraoxon solution $(1 \mathrm{mM})$ for $1 \mathrm{~h}$ at $25^{\circ} \mathrm{C}$ and the PNP density in the solution was measured.

Fig. 1 shows an SEM image of the $E$. coli-attached SWNT film. The overall structure of this film is based on the structure of the SWNTs, which serve as the framework of the film. The cantilever electrodes are connected to each other by the SWNTs, which resemble a suspension bridge that connects the ends of the electrodes. This structure has some advantages for microfluidic application. First, the E. coli-attached SWNT film is suspended from the surface of the substrate and has a porous structure. Therefore, reactants transfer by convection and the reaction
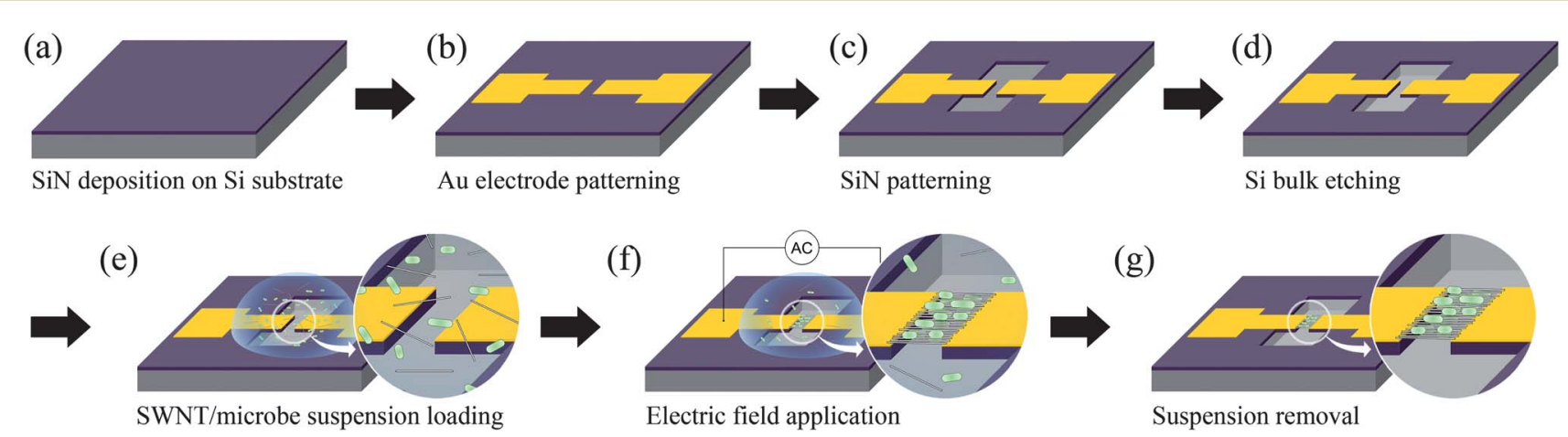

(f)

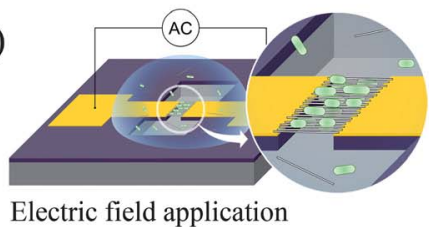

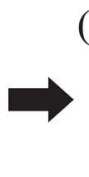

(g)

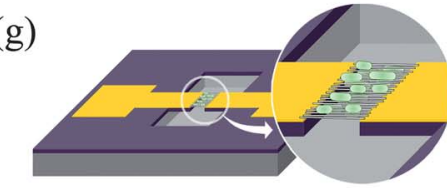

Suspension removal

Scheme 1 Schematic representation of the fabrication process of SWNT film with attached microbes. 

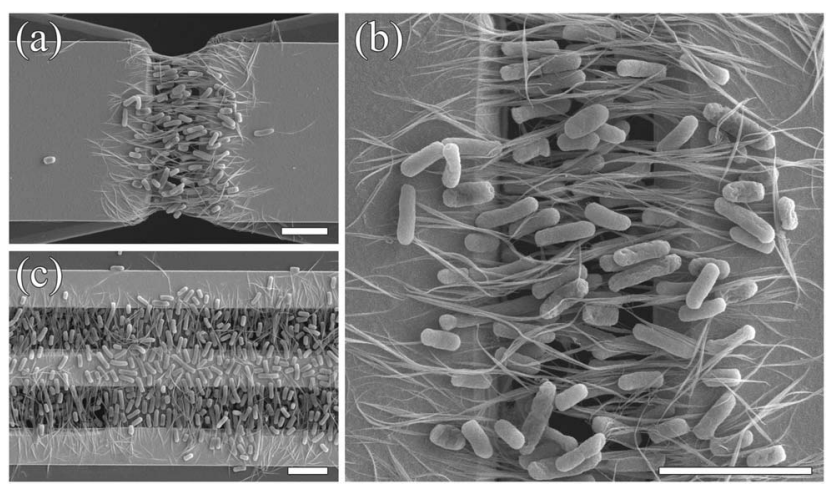

Fig. 1 SEM images of E. coli-attached SWNT film. (a) The entire configuration and (b) a magnified view of the gap between the two electrodes. An AC voltage with an amplitude of $6 \mathrm{~V}_{\mathrm{PP}}$ and a frequency of $1 \mathrm{MHz}$ was applied between the two electrodes, across the mixed SWNT-E. coli suspension, for $10 \mathrm{~s}$. (c) the E. coli-attached SWNT film formed along the microfluidic channel path. An AC voltage with an amplitude of $7 \mathrm{~V}_{\mathrm{PP}}$ and a frequency of $1 \mathrm{MHz}$ was applied between the two electrodes, across the mixed SWNT-E. coli suspension, for $20 \mathrm{~s}$ (scale bar: $5 \mu \mathrm{m}$ ).

area in this structure is greater than that of films attached to the surface of substrates. When using microbial whole-cell enzymes in a microfluidic application, the mass transfer efficiency of the reactants is an important factor influencing the performance of the microfluidic device. Second, electrical signals can be applied to, and measured from, the cells because the E. coli is strongly attached to the SWNTs. Furthermore, the small contact area between $E$. coli and the SWNTs minimizes the extra stress caused by the interaction between the cell wall and the immobilization material. In fact, this configuration maximizes the contact area of the $E$. coli with the reactants and can thereby maximize the reaction efficiency.

Because the electrodes can take any number of positions and shapes, the microbe-attached SWNT film can be fabricated in whatever shape is needed. Fig. 1c shows E. coli-attached SWNT film that formed along the microfluidic channel path. This type of microbe-attached SWNT film can be formed easily by patterning the electrodes along the microchannel, even when the design is complex. The only requirement for film fabrication is that the width of the gap between any given pair of electrodes must be uniform. The shape and area of microbe-attached SWNT film can be adjusted to suit various microfluidic applications.

As the microbial density of the film increases, so does the reaction efficiency of the film. However, when the microbial density is too high, the reaction efficiency may begin to decrease due to limitation of mass transfer. ${ }^{32}$ It is therefore important to regulate the microbial density of the film. The cell density of the film can be controlled by varying the $E$. coli density in the SWNT-E. coli mixed suspension, the electric field intensity, or the duration of electric field application. Fig. 2 shows the cell density of film created under various conditions. For these experiments, we used a device with $20 \mu \mathrm{m}$-wide electrodes spaced $5 \mu \mathrm{m}$ apart (as in Fig. 1a). On average, the 2-dimensional area of $E$. coli is about $1 \mu \mathrm{m}^{2}$. Therefore, the cell count per unit area $\left(1 \mu \mathrm{m}^{2}\right)$ can be considered as the percentage of $E$. coli in the entire film area. Fig. 2a shows the cell count per unit area for film made using suspensions with various $E$. coli densities under the same electric field intensity and duration $\left(6 \mathrm{~V}_{\mathrm{pp}}, 1\right.$ $\mathrm{MHz}, 5 \mathrm{~s})$. The cell concentration of the film increased with increasing suspension cell density. However, this relationship is not linear. The amount by which the cell density of the film increases tends to become smaller as the cell density of the suspension increases. This is because the density of SWNT was almost the same in each film, which limited the quantity of cells that could be attached to the SWNT. Fig. $2 \mathrm{~b}$ shows the density of cells in films created using different durations of electric field while holding the suspension cell density and current characteristics constant $\left(\mathrm{OD}_{600}=0.05,6 \mathrm{~V}_{\mathrm{pp}}, 1 \mathrm{MHz}\right)$. The cell density of the film was proportional to the duration of electric field application. Fig. 2c shows the cell density of film created using different electric field intensities (peak-to-peak voltage) while holding the suspension cell density and current duration constant $\left(\mathrm{OD}_{600}=0.05,5 \mathrm{~s}, 1 \mathrm{MHz}\right)$. It became difficult to accurately count the cells when $8 \mathrm{~V}_{\mathrm{pp}}$ was applied because the SWNT and cells were so dense that some cells were occluded.

Formation of film failed at field durations of less than $5 \mathrm{~s}$ (Fig. 2b) or voltages below $6 \mathrm{~V}_{\mathrm{PP}}$ (Fig. 2c). This is because too little SWNT aligned between the electrodes. Electric fields applied for longer than $20 \mathrm{~s}$ (Fig. 2b) and peak-to-peak voltages greater than $8 \mathrm{~V}_{\mathrm{PP}}$ (Fig. 2c) also cause problems. First, the SWNT and cell density of the film is increased. This reduces the (a)

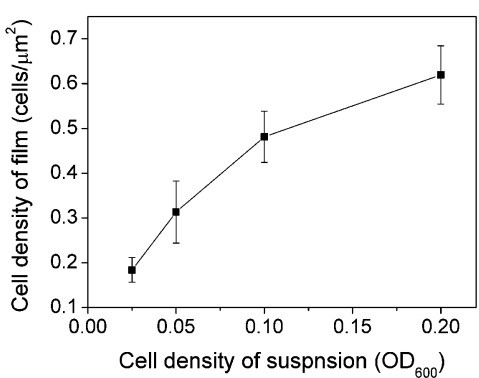

(b)

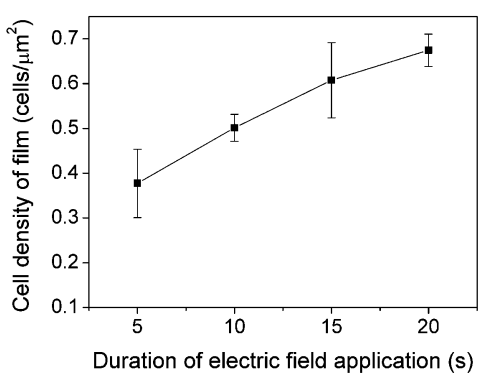

(c)

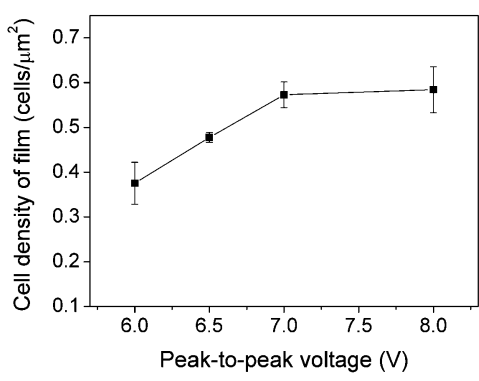

Fig. 2 E. coli density in microbe-attached film. (a) Density of $E$. coli in the film with increasing $E$. coli density in the suspension with an electric field intensity of $6 \mathrm{~V}_{\mathrm{PP}}, 1 \mathrm{MHz}$ for $5 \mathrm{~s}$, (b) density of $E$. coli in the film with increasing duration of $6 \mathrm{~V}_{\mathrm{PP}}, 1 \mathrm{MHz}$ electric fields for suspensions with $\mathrm{OD}_{600}=0.05$, and (c) density of $E$. coli in the film with increasing electric field intensity (peak-to-peak voltage, $5 \mathrm{~s}, 1 \mathrm{MHz}$ ) for solutions with $\mathrm{OD}_{600}=0.05$. Error bars indicate standard deviations. 
(a)

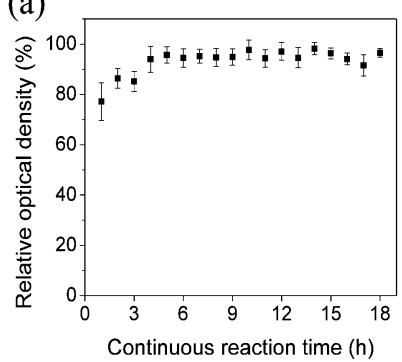

(b)

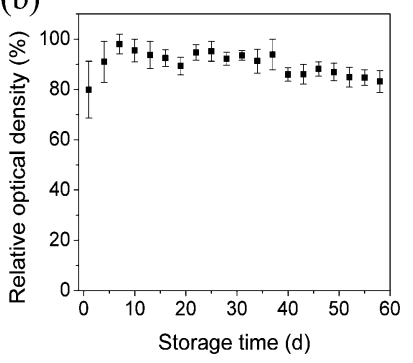

Fig. 3 (a) Continuous reaction time and (b) long-term storage stability of microbe-attached SWNT film. The paraoxon hydrolysis reaction was performed at $25{ }^{\circ} \mathrm{C}$ for $1 \mathrm{~h}$ at (a) every $1 \mathrm{~h}$ and (b) every 3 days and analyzed by measuring the absorbance at the $\lambda$ of $400 \mathrm{~nm}$. Each value represents the means of (a) five independent devices and (b) four independent devices, and the error bars indicate standard deviations.

porosity of the film and cells may burst as a result of watermeniscus-induced pressure when the SWNT density is too high. Second, increasing exposure to an electric field is disadvantageous for cell viability. Varying the cell density of suspensions does not result in these problems. Furthermore, the adjustable range of cell density in films is greater when suspension cell density is varied than when electric field parameters are varied. Consequently, to adjust the microbial density of films, it is most effective to vary the microbial density of the suspension and to alter electric field parameters only within a verified range.

When microbe-immobilized films are used in microfluidic applications, the reaction activity of microbes in the film must be maintained during operation. To investigate stability of the film, we tested the continuous reaction time and long-term storage time. Fig. 3a shows the continuous reaction time of films made using recombinant $E$. coli that expressed OPH. The cell activity was maintained until the end of the $18 \mathrm{~h}$ test. This result indicates that our film is stable enough for even longterm operating systems. The long-term storage stability of the film was evaluated (Fig. 3b). The E. coli-attached SWNT film retained $90 \%$ of its maximum activity for 37 days. This is an excellent result in comparison to those of previous studies. ${ }^{21,33}$, ${ }^{34}$ Additionally, live/dead assay was conducted to confirm cell viability after immobilization process. The results show that our immobilization method for microbes does not have an effect on the cell viability (Fig. S1†).

\section{Conclusions}

In conclusion, this study was motivated by the fact that although microbes have been used extensively in various industrial and scientific applications, they have not been used widely for microfluidic applications because it is difficult to properly immobilize them in a microfluidic device. In this study, we developed a site-specific, simple, fast, and efficient method for microbial immobilization to a microfluidic system. Using this method, we fabricated an SWNT film with attached microbes. The film has a suspended and porous structure that is advantageous for mass transfer and reaction area. In addition, all of the parts, including electrodes, SWNT, and microbes,

are electrically connected. Furthermore, the shape and density of the microbe-attached SWNT film can be easily controlled by adjusting the design of the electrodes, cell density of the suspension, and the electric field. The excellent stability of this film was demonstrated by measuring continuous reaction time and long-term storage time. We believe that these features of our method will be beneficial to research into microfluidic systems using microbes and may eventually lead to the wide use of microbes in various microfluidic applications.

\section{Acknowledgements}

This work was supported by the National Research Foundation of Korea (NRF) grant funded by the Korea government (MEST) (no. 2012R1A2A2A06047424). This work was also supported by the National Research Foundation of Korea (NRF) grant funded by the Korea government (MEST) (no. 2012R1A1A2007580).

\section{Notes and references}

1 J. M. Clomburg and R. Gonzalez, Appl. Microbiol. Biotechnol., 2010, 86, 419-434.

2 H. P. Sørensen and K. K. Mortensen, J. Biotechnol., 2005, 115, 113-128.

3 F. Baneyx, Curr. Opin. Biotechnol., 1999, 10, 411-421.

4 F. J. M. Mergulhão, D. K. Summers and G. A. Monteiro, Biotechnol. Adv., 2005, 23, 177-202.

5 H. Ben-Yoav, A. Biran, R. Pedahzur, S. Belkin, S. Buchinger, G. Reifferscheid and Y. Shacham-Diamand, Electrochim. Acta, 2009, 54, 6113-6118.

6 H.-S. Lee, W. F. J. Vermaas and B. E. Rittmann, Trends Biotechnol., 2010, 28, 262-271.

7 L. E. de-Bashan and Y. Bashan, Bioresour. Technol., 2010, 101, 1611-1627.

8 H.-Y. Wang, A. Bernarda, C.-Y. Huang, D.-J. Lee and J.-S. Chang, Bioresour. Technol., 2011, 102, 235-243.

9 T. Cai, S. Y. Park and Y. Li, Renewable Sustainable Energy Rev., 2013, 19, 360-369.

10 L. Su, W. Jia, C. Hou and Y. Lei, Biosens. Bioelectron., 2011, 26, 1788-1799.

11 Z. Du, H. Li and T. Gu, Biotechnol. Adv., 2007, 25, 464-482.

12 M. B. Cassidy, H. Lee and J. T. Trevors, J. Ind. Microbiol., 1996, 16, 79-101.

13 S. V. Dzyadevych, A. P. Soldatkin, Y. I. Korpan, V. N. Arkhypova, A. V. El'skaya, J.-M. Chovelon, C. Martelet and N. Jaffrezic-Renault, Anal. Bioanal. Chem., 2003, 377, 496-506.

14 S. Matosevic, N. Szita and F. Baganz, J. Chem. Technol. Biotechnol., 2011, 86, 325-334.

15 D. G. Kang, G.-B. Lim and H. J. Cha, J. Biotechnol., 2005, 118, 379-385.

16 J. H. Choi and S. Y. Lee, Appl. Microbiol. Biotechnol., 2004, 64, 625-635.

17 A. Mulchandani, P. Mulchandani, I. Kaneva and W. Chen, Anal. Chem., 1998, 70, 4140-4145.

18 A. Mulchandani, I. Kaneva and W. Chen, Anal. Chem., 1998, 70, 5042-5046. 
19 R. D. Richins, I. Kaneva, A. Mulchandani and W. Chen, Nat. Biotechnol., 1997, 15, 984-987.

20 M. Shimazu, A. Mulchandani and W. Chen, Biotechnol. Bioeng., 2001, 76, 318-324.

21 C. S. Kim, B.-H. Choi, J. H. Seo, G. Lim and H. J. Cha, Biosens. Bioelectron., 2013, 41, 199-204.

22 I. Moreno-Garrido, Bioresour. Technol., 2008, 99, 3949-3964.

23 J. K. Park and H. N. Chang, Biotechnol. Adv., 2000, 18, 303319.

24 S. H. Song, S. S. Choi, K. Park and Y. J. Yoo, Enzyme Microb. Technol., 2005, 37, 567-573.

25 A. Sanchis, A. P. Brown, M. Sancho, G. Martínez, J. L. Sebastián, S. Muñoz and J. M. Miranda, Bioelectromagnetics, 2007, 28, 393-401.

26 A. G. Venkatesh and G. H. Markx, J. Phys. Appl. Phys., 2007, 40, 106-113.

27 R. Zhou, P. Wang and H.-C. Chang, Electrophoresis, 2006, 27, 1376-1385.
28 T. An, K. S. Kim, S. K. Hahn and G. Lim, Lab Chip, 2010, 10, 2052.

29 J. T. Cang-Rong and G. Pastorin, Nanotechnology, 2009, 20, 255102.

30 D. G. Kang, C. S. Kim, J. H. Seo, I. G. Kim, S. S. Choi, J. H. Ha, S. W. Nam, G. Lim and H. J. Cha, Biotechnol. Prog., 2012, 28, 925-930.

31 H. J. Busscher, R. J. B. Dijkstra, D. E. Langworthy, D. I. Collias, D. W. Bjorkquist, M. D. Mitchell and H. C. Van der Mei, J. Colloid Interface Sci., 2008, 322, 351357.

32 J. H. Flemming, H. K. Baca, M. Werner-Washburne, S. M. Brozik and G. P. López, Sens. Actuators, B, 2006, 113, 376-381.

33 J. Kumar and S. F. D'Souza, Biosens. Bioelectron., 2011, 26, 4399-4404.

34 J. Kumar and S. F. D'Souza, Biosens. Bioelectron., 2010, 26, 1292-1296. 